\title{
P151 Microvascular Dysfunction is Associated with Impaired Beta-cell Function: The Maastricht Study
}

\author{
Wenjie Li, Alfons Houben, Tos Berendschot, Carroll Webers, Abraham Kroon, Marleen van Greevenbroek, \\ Carla van der Kallen, Ronald Henry, Simone Sep, Pieter Dagnelie, Nicolaas Schaper, Simone Eussen, \\ Casper Schalkwijk, Miranda Schram, Coen Stehouwer
}

Maastricht University Medical Center, Maastricht, The Netherlands

\section{ABSTRACT}

Background: The pathophysiological mechanism underlying beta-cell dysfunction in type 2 diabetes (T2D) is not fully understood. Recent animal studies suggest that microvascular dysfunction (MVD) may lead to insufficient delivery of oxygen and nutrients to beta-cells as well as an attenuated delivery of insulin into the circulation $[1,2]$. We aimed to investigate the association of MVD with beta-cell function in a population-based cohort study.

Methods: In The Maastricht Study $(n=2802,51.5 \%$ men, aged $59.8+8.2$ years, $22.9 \%$ T2D) [3], we determined plasma endothelial biomarkers (vWF, sE-selectin, sICAM-1, sVCAM-1), retinal microvascular diameters (CRAE, CRVE), flicker lightinduced retinal microvascular dilation (DVA), heat-induced skin hyperaemia (LDF), and beta-cell function (OGTT: C-peptide to glucose ratio t0 (CP0/G0 ratio), CP30/G30 ratio, CP120/G120 ratio, beta-cell glucose sensitivity, potentiation, and rate sensitivity). Associations were adjusted for age, sex, waist circumference, systolic blood pressure, smoking, alcohol intake, lipid profile, use of antihypertensive and/or lipid-modifying drugs, and Matsuda index.

Results: Multivariable adjusted analyses showed that a higher levels of plasma endothelial biomarkers and wider retinal venules (CRVE) were associated with greater $\mathrm{CP} 0 / \mathrm{G} 0$ ratio $(\mathrm{stB}=0.13,95 \% \mathrm{CI}(0.10 ; 0.16), p<0.001 ; \mathrm{stB}=0.03,(0.003 ; 0.07), p=0.031$, respectively; Figure 1). Lower flicker light-induced retinal arteriolar dilation (\%) was associated with lower CP30/G30 ratio $(\mathrm{stB}=0.06,(0.01 ; 0.10), p=0.011)$ and beta-cell glucose sensitivity $(\mathrm{stB}=0.05,(0.01 ; 0.10), p=0.025)$. Lower heat-induced skin hyperaemia (\%) was associated with lower beta-cell glucose sensitivity ( $\mathrm{stB}=0.06,(0.003 ; 0.11), p=0.038$ ).

Conclusion: MVD is associated with higher fasting insulin secretion, and lower CP30/G30 ratio and beta-cell glucose sensitivity during OGTT. These results suggest that MVD may contribute to an augmented fasting insulin secretion as well as attenuated insulin secretion during OGTT. This may contribute to beta-cell failure.

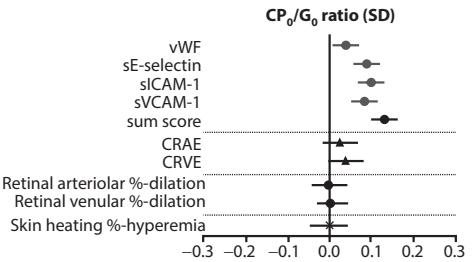

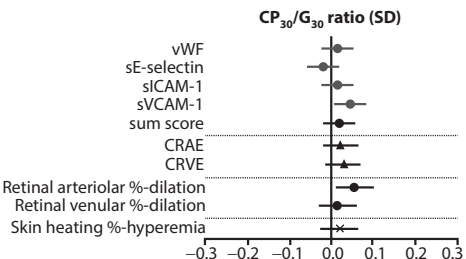

Figure 1

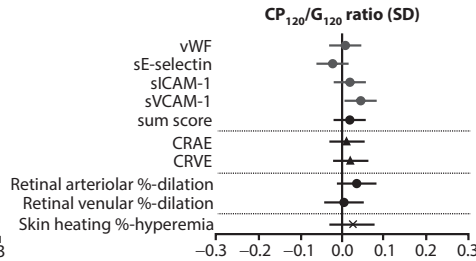

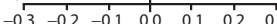

\section{REFERENCES}

[1] Hashimoto S, Kubota N, Sato H, Sasaki M, Takamoto I, Kubota T, et al. Insulin receptor substrate-2 (Irs2) in endothelial cells plays a crucial role in insulin secretion. Diabetes 2015;64:876-86.

[2] Kostromina E, Wang X, Han W. Altered islet morphology but normal islet secretory function in vitro in a mouse model with microvascular alterations in the pancreas. PLoS One 2013;8:e71277.

[3] Schram MT, Sep SJ, van der Kallen CJ, Dagnelie PC, Koster A, Schaper N, et al. The Maastricht Study: an extensive phenotyping study on determinants of type 2 diabetes, its complications and its comorbidities. Eur J Epidemiol 2014;29:439-51.

(c) 2019 Association for Research into Arterial Structure and Physiology. Publishing services by Atlantis Press International B.V. This is an open access article distributed under the CC BY-NC 4.0 license (http://creativecommons.org/licenses/by-nc/4.0/). 